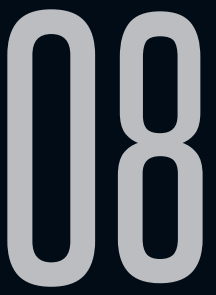

\title{
UMA LEITURA STEAMPUNK DA OBRA A LIÇÃO DE ANATOMIA DO TEMÍVEL DR. LOUISON (2014), DE ENÉIAS TAVARES
}

\author{
Adriana Claudia Martins (UFSM/RS)
} Suellen Cordovil da Silva (UNIFESSPA)

Recebido em 04 nov 2019. Adriana Claudia Martins é Doutora e Professora Aprovado em 26 fev 2020. voluntária em Educação na UFSM; doutoranda em Letras em Estudos Literários também na UFSM; Mestre em Letras em Estudos Linguísticos pela UCPel; Especialista em Língua Portuguesa e Literatura; Graduada em Língua Portuguesa e Inglesa e respectivas Literaturas pela UNIFRA.

Suellen Cordovil da Silva é doutoranda em Letras em Estudos Litrários pela UFSM; Professora Assistente Nível II na UNIFESSPA e Mestre em Letras em Estudos Literários.

Resumo: Neste artigo, analisaremos os elementos do subgênero de ficção científica intitulado steampunk a partir da obra A lição de anatomia do temível Dr. Louison (2014), de autoria de Enéias Tavares. Os estudos de Causo (2015), Pegoraro (2012a; 2012b) e Roberts (2018) são as bases que fundamentam teoricamente o estudo. Neste texto consideramos a relação dos personagens de domínio público dos clássicos da literatura nacional e investigamos como esses personagens foram recriados nesta narrativa steampunk. Assim, averiguamos as características ficcionais dessa narrativa imbricando-as à ficção considerada. Neste ínterim, apreendemos que a ficção científica alcançou seu espaço com a Revolução 
Industrial e com a mobilização dos recursos da ciência, os quais contribuíram para o desenvolvimento dos conceitos científicos.

Palavras-chave: A Lição de Anatomia do Temível Dr. Louison; Steampunk; Fiç̧ão Científica; Revolução Industrial.

Abstract: In this article, we will analyze the elements of science fiction subgenre entitled steampunk from the book $A$ lição de anatomia do temível Dr. Louison (2014), written by Enéias Tavares. The studies from Causo (2015), Pegoraro (2012a; 2012b) and Roberts (2018) are the basics that theoretically underlie the study. In this text, we consider the relationship of the public domain characters of national literature classics and to investigate how these characters were recreated in this steampunk narrative. Thus, we ascertained the fictional features of this narrative by merging them with the considered fiction. In the meantime, we learn that science fiction reached its place with the Industrial Revolution and the mobilization of science resources, which contributed to the development of scientific concepts.

Keywords: A lição de anatomia do temível Dr Louison; Steampunk; Science fiction; Industrial Revolution.

\section{INTRODUÇÃO}

Neste artigo, analisamos algumas características do subgênero de ficção científica chamado steampunk presentes no discurso narrativo da obra A lição de anatomia do temível Dr. Louison (2014), de autoria de Enéias Tavares. Ao identificarmos que o autor traz elementos do steampunk, discutimos os diálogos de sua narrativa com a literatura clássica nacional e com a proposta da série Brasiliana Steampunk, concebida por Tavares. Nessa obra encontram-se personagens da literatura brasileira, os quais são reinventados em 
um espaço sulista, recriado como parte de uma história alternativa do Brasil e do mundo. Desse modo, discutimos inicialmente o steampunk como um subgênero da ficção científica. Depois, descrevemos as relações de alguns dos personagens ressignificados de Tavares originários das obras de literatura brasileira em domínio público. Por fim, analisamos aspectos da ficção científica steampunk no modo narrativo do autor.

Os estudiosos da área sinalizam pontos importantes referentes à ficção científica e, neste ínterim o gênero de ficção científica é considerado como um constante movimento popular, com variados formatos midiáticos. Temos as graphic novels, os livros, os jogos e os filmes que são espaços conquistados pela ficção científica a cada dia, contexto em que seus leitores são atraídos pelos seus conteúdos, os quais visam um imaginário racionalizado. O discurso ficcional descreve uma proximidade com elementos de cunho científico e tecnológico e, desse modo, a construção da narrativa da ficção científica exige uma variedade de elementos que nos apresentam um futuro mais tecnológico.

Os pesquisadores brasileiros Roberto Causo (2015) e Éverly Pegoraro (2012a; 2012b) discutem os caminhos da ficção científica no Brasil e no mundo, enquanto que Adam Roberts (2018) trabalha com um processo de descrição da história da ficção científica desde os preconceitos sofridos pelo gênero até as conquistas das massas, e de ordem cronológica, desde a novela antiga até os fins do século XX.

Em Tavares, os resgates dos personagens das obras brasileiras antigas transmutam-se em um universo de ciência avançada. Consideramos que esses personagens são recriados em uma nova 
trama de investigações. Os personagens da literatura clássica deixam o Rio de Janeiro de Todos os Orixás (o nome da metrópole no contexto ficcional do romance) e seguem em suas descobertas rumo a Porto Alegre, em busca de respostas para tantos desastres, conflitos sociais e uma nova forma de se viver.

A ficção científica produziu várias vertentes e um deles é o steampunk. Os elementos próprios do steampunk serão reelaborados na narrativa de $A$ lição de anatomia do temível Dr. Louison (2014), por meio das ações de seus personagens.

\section{O QUE É O STEAMPUNK?}

Uma história alternativa do século $\mathrm{XIX}$ e início do século $\mathrm{XX}$ com nuances futuristas pode ser considerada como pertencente ao subgênero steampunk. Além disso, o steampunk ganhou as cores de um movimento cultural em diversas partes do mundo. No entanto, discutimos neste texto a literatura e suas características, na narrativa brasileira de Enéias Tavares. A palavra steampunk foi utilizada inicialmente por três autores desse subgênero, pioneiros do steampunk com as seguintes obras: Morlock Night (1979) e Infernal Devices: A Mad Victorian Fantasy (1987), de K. W. Jeter; The Ape-Box Affair (1978), The Idol's Eye (1984) e Homunculus (1986), de James P. Blaylock; e The Anubis Gates (1983), de Tim Powers. Chaves (2018), em seu artigo "Cinema retrofuturista e steampunk: possíveis origens de um subgênero literário", alega que "[t]odos eles apresentavam enredos ambientados na Inglaterra vitoriana, uma coexistência entre tecnologia e ocultismo, e a interação entre personagens históricos, fictícios e tomados de empréstimo dos clássicos scientific romances do século XIX" (CHAVES, 2018, p.238-239). 
Se pensarmos, no que tange ao século XIX, nas diferenças entre o contexto inglês - no qual a noção de império é valorizada como ideal político e nacional - e o norte-americano, este dividido pela Guerra da Secessão, há uma profunda diferença entre ambos. Assim, pode-se compreender que os autores norte-americanos, ao retornar ao contexto vitoriano inglês, abrem possibilidades imaginativas de revisitarem de forma crítica seu próprio passado colonialista e a própria formação dos Estados Unidos. O mesmo faz, porém com outra chave, Enéias Tavares, ao recriar em sua obra aspectos do passado colonialista brasileiro, de modo a situar o período histórico da Primeira República no Brasil e as novas e possíveis complexidades de nível artístico, social e político com a nuance estilística steampunk.

A autora Éverly Pegoraro (2015), em seu livro intitulado No compasso do tempo steampunk: A canção do silêncio desenvolve a perspectiva do steampunk como um movimento cultural. Além disso, Pegoraro (2012b, p.391) afirma que, "os steampunks lançam um olhar para o passado impregnado das percepções do presente e, simultaneamente, imaginam um futuro que poderia ter se realizado". Desse modo, o steampunk desdobra-se na década de 1980 como um subgênero oriundo da ficção científica. Essa manifestação artística e cultural justifica-se pela utilização, por exemplo, da tecnologia do vapor, por esta "ter revolucionado as formas de produção e estar no cerne da Revolução Industrial do século XIX: uma era de grandes mudanças com novos modos de transporte e técnicas produtivas, além das descobertas científicas, medicinais e de armamentos" (PEGORARO, 2012 b, p.393).

Em compasso com a forma estética steampunk, infere-se que o seu retrofuturismo carrega a descrição da palavra "retrô", 
que significa um estilo ou uma característica do passado ou de outros tempos, que na contemporaneidade caiu em desuso, mas que pode, eventualmente, ser renovado por recursos criativos da atualidade. Segundo Torres (2007), pode-se compreender que o retrofuturismo é uma forma de "capacidade de visualizar o futuro a partir do momento presente. [...] O Retrofuturismo seria a visão passada sobre o futuro, se o Futurismo é a antecipação dos fatos, o Retrofuturismo é a lembrança dessa antecipação" (TORRES, 2017, $\mathrm{s} / \mathrm{p})$. O steampunk lida ou reapropria a condição da possibilidade de um futuro de tecnologias em um passado com característica vitorianas. Para Joana Garcia Costa (2013), a literatura steampunk define-se deste modo:

Desde o seu início, a literatura steampunk lida com a questão do "E se?". E se a bomba atómica tivesse sido inventada durante o reinado da Rainha Vitória? $E$ se os vitorianos tivessem acesso à tecnologia de hoje? E se personagens da literatura vitoriana fossem figuras históricas? Este constante misturar de fantasia e realidade, de factos históricos e personagens fictícias, criam um mundo de fantasia singular mas que, ao mesmo tempo, atrai pela sua peculiaridade. (COSTA, 2013, p.16)

Do mesmo modo como Pegoraro (2012b) considera o steampunk como uma manifestação cultural, os autores Bruno Anselmi Matangrano e Enéias Tavares também confirmam o steampunk como um movimento artístico. Na obra Fantástico brasileiro: o insólito literário do romantismo ao fantasismo (2018), de Matangrano e de Tavares, os autores argumentam no capítulo dezessete, intitulado a "Viagem a um passado futurista: o steampunk", que a vertente literária steampunk "é uma das 
formas mais populares de retrofuturismo, na qual, partindo-se de uma ambientação vitoriana, entre o final do século XIX e início do $X X$, muitas vezes underground, superpoluída e decadente - e por isso punk" (p.189) e, além disso, eles descrevem alguma obras do steampunk nas décadas de 80 e 90, como por exemplo as obras de língua inglesa intituladas Morlock Night (1979), de Jeter, Os portais de Anúbis (1983), de Powers, Homunculus (1986), de Blaylock, e A máquina diferencial (1990), de William Gibson e Bruce Sterling. Desse modo, destaca-se que a era vitoriana é considerada um período da história do Reino Unido e do Império Britânico, entre 1837 a 1901. No Brasil, há períodos em que também tivemos monarcas e regime imperialista; assim, o próprio steampunk avançou para além da era vitoriana, e nesse contexto o romance de Tavares é ambientado já na Primeira República brasileira.

Roberto Causo (2015) interpreta o contexto da ficção científica no Brasil em ondas históricas, em seu artigo intitulado "Esboço de uma história da crítica de ficção científica no Brasil", no livro Cartografias para a ficção científica mundial: cinema e literatura, organizado por Alfredo Suppia, publicado em 2015. Nesse artigo, Causo descreve as três ondas e aponta questões críticas sobre a ficção científica brasileira, juntamente com os estudiosos, escritores e pesquisadores do assunto no Brasil. Segundo o autor, a Primeira Onda foi por volta de 1957 a 1972, tendo se desgastado até 1982. Então, entre 1982 e 2015 tem-se a Segunda Onda; e de 2004 até o nosso presente, nota-se que se estabelece a Terceira Onda da Ficção Científica Brasileira.

Em Fractais tropicais (2018), antologia organizada por Nelson de Oliveira, tem-se uma compilação de histórias extraídas das três 
ondas de ficção científica brasileira, histórias que vão, na Primeira Onda, de 1961 até 1980; na Segunda Onda, de 1981 até 2000; e na Terceira Onda de 2001 até 2020. No prefácio da obra, descreve a ficção científica como uma forma de literatura em que "as pessoas fazem as mesmas coisas por meio da engenharia genética, da mecânica quântica, da inteligência artificial etc., ou seja, graças à ciência e à tecnologia" (OLIVEIRA, 2018, p.10).

Além disso, Oliveira apresenta algumas características de uma obra considerada de ficção científica: elementos de ciência e tecnologia fundamentando o enredo; depois, as inserções de ícones, tipos e estereótipos ligados à ciência e à tecnologia: a astronave, o alienígena, o androide, o ciborgue, a inteligência artificial, a máquina do tempo, a realidade alternativa; por fim, ele defende que deve haver uma grande reformulação da sociedade, de natureza utópica ou distópica (OLIVEIRA, 2018).

Adam Roberts (2018), no livro intitulado A verdadeira história da ficção científica: Do preconceito à conquista das massas, recupera autores e momentos importantes para a construção da ficção científica como um todo. De modo que ele sinaliza o início da história da ficção científica com a Reforma Protestante na Europa, em meados dos 1600. No entanto, grande parte dos pesquisadores atesta o seu surgimento a partir da publicação, no século XIX, de Frankenstein ou O moderno Prometheu (1818), de Mary Shelley.

Martins e Santos, no artigo intitulado "A robótica e a ficção científica: primeiras interações" (2019), fazem um levantamento do conceito da ficção científica e de como o robô se manifesta-se nessa ficção, com suas elucubrações e citando os autores Adams 
Roberts (2018), Isaac Asimov (1984), Muniz Sodré (1978), Raul Fiker (1985), Georges Giralt (1997) e Roberto C. Belli (2012). Martins e Santos apresentam o conceito de ficção científica de Asimov, autor da obra Eu, robô (1950). Segundo as autoras, há um contraste quanto ao que Adams Roberts afirma, em relação ao surgimento da ficção científica:

Segundo Asimov, a Fiç̧ão Científica é um gênero que somente poderia ter surgido a partir do ano de 1800 , pois ele exige uma narrativa que apresente uma percepção do homem acerca das mudanças sociais decorrentes dos avanços tecnológicos. Ele acreditava que antes da Revolução Industrial as mudanças sociais eram quase estáticas, tornando-se imperceptíveis pelo homem dentro do seu tempo de vida, e que foi a industrialização a responsável por gerar avanços tecnológicos que ocasionaram mudanças mais céleres, tornandoas, assim, perceptíveis pela sociedade que foi beneficiada (ou não) pelas tecnologias. (MARTINS; SANTOS, 2019, p.4)

Enfim, sem o aprofundamento da questão de onde vieram primeiro os rumos e os conceitos da ficção científica, frisamos que ela ressalta a ciência como um elemento fundamental para a sua construção. Para uma discussão da ciência na corrente steampunk, apontamos que Roberts descreve o modelo da ciência na era vitoriana, afirmando que no período ocorreu uma espécie de casamento da arte com a ciência. Roberts destaca ainda que a modernidade não compactua com essa formulação da fusão da arte com a ciência, pois para a modernidade, segundo o autor, não se pode encontrar uma precisão estética de assuntos científicos. 
Para o autor a ciência "se torna uma moldura filosófica idealista mais ou menos restritiva (como a maioria dos cientistas afirma) não pela falta de qualidade ou pressão ideológica, mas pela simples natureza das coisas 'lá fora'” (ADAMS, 2018, p.49). Mas, vale ressaltar que a arte e a ciência são interligadas e caminham juntas. No caso, a tecnologia "por outro lado, é o discurso de ferramentas e máquinas, sendo as ferramentas extensões do trabalho humano, como martelo e serras, e as máquinas, dispositivos que se mantêm à parte do trabalhador" (ADAMS, 2018, p.49). Roberts (2018) trouxe os autores Darko Suvin, Patrick Parrinder, Damien Broderick, Samuel Delany, Brian Stableford, John Clute e Peter Nicholls para uma discussão crítica, porém ele afirma que não é fácil alcançar um consenso do que seria a ficção científica.

A ficção científica tenta explorar a ciência de modo que o leitor compreenda o universo científico em doses gradativas ou imediatas. O steampunk, por sua vez, recria elementos culturais do período vitoriano ocorrido na Inglaterra no século XIX. Assim, o que caracteriza o steampunk é um discurso delineado em aspectos tecnológicos e futuristas, com isso as características retrofuturista do steampunk são dramatizadas em um contexto do passado reimaginado por meio de elementos de uma tecnologia futurista.

Com base na descrição de Jeff VanderMeer e S.J. Chambers, no livro Steampunk Bible (2011), a lição chave do Steampunk não é explicar o passado, mas sim apresentar a instabilidade e obsolescência dos tempos presentes, nos quais o passado está diluído em referencias, releituras e transposições. Assim, uma das possíveis razões da popularidade do steampunk estaria no fato dos leitores darem-se 
conta de que o mundo em que vivem continua resgatando o passado de algum modo (VANDERMEER; CHAMBERS, 2011, p.13).

Interessa-nos sublinhar, que a descrição da palavra steam significa vapor, enquanto punk traz uma ideia de subversão das leis daquela sociedade e sua cultura autoritária, além de sua industrialização voraz, principalmente nas primeiras décadas do século XX, que desumanizavam o ser humano. Assim, o steampunk constitui-se como um subgênero que faz alusão ao passado do século XIX com as visões da tecnologia e da estética dos séculos $\mathrm{XX}$ ao $\mathrm{XXI}$.

\section{O PASSADO RETROFUTURISTA EM A BRASILIANA STEAMPUNK}

O romance $A$ lição de anatomia do temível Dr. Louison se passa na Porto Alegre retrofuturista do início do Século XX. O leitor dessa obra mergulha em um universo de vapor e sons das locomotivas e em uma ambientação de máquinas com as suas engrenagens diversas. No cenário criado pelo escritor Enéias Tavares, somos apresentados a Isaías Caminha, jornalista carioca que vai até a "Porto Alegre dos Amantes" para cobrir a prisão de Antoine Louison, acusado de uma série de assassinatos que vinham apavorando a capital gaúcha.

Entende-se que a série Brasiliana Steampunk, a qual o romance estudado pertence, dá uma nova valoração aos personagens da literatura clássica brasileira que foram absorvidos no enredo e transformados em um outro percurso narrativo de ficção científica. Essa é em uma estratégia descrita por Julia Kristeva (1974, p.64) como: "todo texto se constrói como mosaico de citações, todo texto é absorção e transformação de um outro texto. Em lugar da noção de intersubjetividade, instala-se a de intertextualidade." 
Dessa forma, Enéias Tavares absorve os personagens da literatura clássica brasileira e dá outras possibilidades de ações a eles, ao projetá-los em um enredo retrofuturista.

Tais personagens clássicos carregam elementos característicos do passado brasileiro, de modo reinventado ou recriado. O mosaico da Brasiliana Steampunk ressignifica esses trabalhos da literatura nacional ao dar outro percurso a personagens como Isaías Caminha, Simão Bacamarte, Rita Baiana, Solfieri, Vitória Acauã. Cada personagem segue alguma continuidade da narrativa anterior de seus livros, porém eles desembocam no espaçotemporal retrofuturista de Porto Alegre. Desse modo, Calegari e Oliveira (2018), em seu artigo "Um personagem, dois mundos: Isaías Caminha em 1909 e em 2014", afirmam que:

Cada capítulo [do romance de Enéias Tavares] apresenta o desenvolvimento das ações por meio de gêneros textuais diferentes, embora sejam desdobramentos da forma epistolar clássica, mantendo o apelo a um controle e uma clareza de sua cronologia, típicos de um inventário investigativo. Assim, tem-se os personagens que fazem parte de uma espécie de "liga da justiça" a qual investiga casos dos vilões nessa trama. (CALEGARI; OLIVEIRA, 2018, p.244)

A história ocorre em meados do século XVIII, quando a sociedade secreta intitulada Parthernon Místico formou a sua primeira geração de associados em 1892, após a inclusão do médico Revocato Porto Alegre, que passou a realizar investigações de vários assassinatos que ocorriam na região de Porto Alegre. $\mathrm{O}$ Parthenon Místico é composto pelos personagens Antoine Louison, Beatriz de Almeida e Souza, Dr. Benignus, Giovanni Fillipeto e 
Solfieri de Azevedo. Em 1896, Vitória Acauã, Bento Alves e Sérgio Pompeu entram no grupo do Parthenon Místico. No mesmo ano, os personagens chamados Revocato e Giovanni saem do Pathernon Místico após a criação da Ordem Positivista Gaúcha. A sociedade secreta apresenta habilidades tecnológicas e místicas empregadas para escaparem de seus obstáculos ou resolverem algum dilema. A obra descreve um mistério em um cenário retrofuturista, de 1911, por meio das gravações dos personagens e a ambientação com zepelins, autômatos e tecnologia retrofuturista. O personagem Louison, ao cometer assassinatos de pessoas ricas e das autoridades na sociedade, é capturado para ser executado por esses crimes. O jornalista Isaías Caminha tenta fazer uma entrevista com o assassino, assim ele conversa com as pessoas da cidade e desvenda gradativamente o motivo de Louison ter assassinado essas pessoas.

O jornalista Isaías Caminha é um personagem da obra Recordações do escrivão Isaías Caminha (1909), de Lima Barreto. Nessa obra clássica narra-se a vida de um jovem jornalista que desistiu da carreira após o suicídio de um amigo. Na narrativa steampunk, o personagem Isaías Caminha chega a Porto Alegre e encontra Acauã, que o convida para participar do Pathernon Místico. Isaías Caminha é encantado por uma donzela indígena, e decide participar das aventuras e investigações do grupo, seguindo, assim, em sua investigação dos crimes do Dr. Louison.

O personagem Dr. Benignus é oriundo da obra Doutor Benignus (1875), de Augusto Emílio Zaluar. Na obra de Zaluar, o cientista Benignus desaparece nas matas brasileiras e é considerado morto. Porém, em Brasiliana Steampunk, o Dr. Benignus é encontrado por Revocato e chamado por ele de cientista cósmico. A personagem 
Vitória Acauã, oriunda da obra Contos amazônicos (1893), escrita por Inglês de Sousa, tornou-se a filha adotiva de um capitão da região amazônica, e tinha ciúmes de sua irmã mais velha, até que se transformou em um pássaro misterioso chamado Acauã. Ela é recriada em A lição de anatomia do temível Dr. Louison, em cujas páginas Vitória se torna uma médium indígena que vive várias aventuras na ilha da névoa. Em seguida, Bento Alves a salva após ela ter sido raptada pela Ordem Positivista Gaúcha, em 1896. Observase que o Parthenon Místico e a Ordem Positivitista Gaúcha são sociedades secretas inimigas, pois a primeira defende uma cidade igualitária e justa, enquanto a Ordem Positivista Gaúcha fazia experimentos científicos com pessoas vivas, como por exemplo em Vitória Acauã.

Os personagens Sérgio Pompeu e Bento Alves são amigos na obra $O$ ateneu (1888), de Raul Pompeia. Bento Alves foi expulso da escola Ateneu, e Sérgio conseguiu entrar em contato com o amigo após um longe tempo de distanciamento. Tavares apropria-se desses personagens e continua a história dos dois amigos, trazendoos para fazer parte do Parthenon Místico nas regiões sulistas.

As mulheres Pombinha, Rita Baiana e Léonie são oriundas da obra O cortiço (1890), de Aluízio de Azevedo. Elas, que saíram de um cortiço do Rio de Janeiro depois que ele foi incendiado, criam uma casa noturna chamada de Palacete dos Prazeres que não aceita robóticos em Porto Alegre. O Palacete dos Prazeres é uma casa noturna de festejos e de encontros diversos.

A personagem Beatriz de Almeida e Souza não tem sua origem de uma obra clássica da literatura brasileira, porém ela apresenta 
grandes autoras negras que por muitos anos não tiveram seu devido espaço na academia como escritoras profícuas. No enredo, Beatriz de Almeida e Souza usa vestimentas masculinas para desenvolver sua carreira de escritora. Essa personagem descreve uma característica de militância constante de mulheres, tentativas de ganharem seus espaços e terem que se utilizar de outros mecanismos, bem como utilizarem nomes relacionados ao gênero masculino para que a sua obra pudesse ser comercializada, como tantas autoras do século XIX, a exemplo de George Sand e George Eliot.

Solfieri de Azevedo é um imortal feiticeiro que conta histórias de horror em uma taverna, conforme descrito em Noite da taverna (1855), de Álvares de Azevedo. Na cidade do Sul, ele torna-se um investigador do oculto e é um dos primeiros integrantes do grupo místico. O médico Simão Bacamarte é visto no Sul, após ter saído da Casa Verde da obra O Alienista (1882), de Machado de Assis, ambientada no interior do Rio de Janeiro (então Guanabara). O personagem passa a cuidar do asilo intitulado São Pedro para criminosos insanos e histéricas descontroladas. O personagem João Romão saiu da mesma obra de Aluízio de Azevedo, onde teve prejuízo com as suas acomodações sendo queimadas, e se torna um vilão que procura fechar o Palace dos Prazeres das três damas. Na região sulista, ele tem uma mão robótica e adota o nome de Gregório de Albuquerque.

Desse enredo que descrevemos, lembramos que a ficção científica pode trazer elementos místico, pois "o universo físico ambiciona sempre se elevar para a preferível existência espiritual; após a morte, os humanos progridem por meio de uma série de encarnações espirituais cada vez mais elevadas" (ROBERTS, 2018, 
p.235). Os personagens são inseridos em um ambiente repleto de seres robóticos e outras formas científicas e tecnológicas decorrente da revolução das máquinas. Esse percurso de aventuras dos personagens da literatura clássica brasileira leva o leitor a revisitar um determinado tempo do passado e redescobrir o universo tecnológico, sem fugir da lógica interna da obra, que mantém a verossimilhança.

\section{O STEAMPUNK EM A LIÇÃO DE ANATOMIA DO TEMÍVEL DR. LOUISON, DE ENÉIAS TAVARES}

Existem diversos elementos steampunk na obra de Tavares que podem ser analisados, como por exemplo: o tempo retrofuturista, o espaço das cidades do Rio de Janeiro e de Porto Alegre e seus elementos tecnológicos avançados para o período do século XIX e ainda, os personagens robóticos ou autômatos. Isso tudo desemboca em uma aventura investigativa do personagem Isaías Caminha em direção à cidade de Porto Alegre.

Observa-se que em o mundo alternativo no século XIX descrevese como um jogo de poder exercido pelas fábricas e estaleiros que empregam a tecnologia da era do vapor, dentro da especulação de determinada tecnologia. O jornalista Isaías Caminha comporta-se, em sua visita à cidade de Porto Alegre, como um flâneur a se deliciar com cada movimento da multidão. Conforme Matangrano define:

Diferentemente do livro em que aparece originalmente, o Caminha reciclado torna-se uma espécie de flâneur decadente à maneira de Baudelaire e a tudo passa a observar, a fruir e a examinar, tanto com a razão quanto com os sentidos, quase como se buscasse encontrar a redenção escondida na balbúrdia da metrópole 
hipertrofiada da Porto Alegre dos Amantes retrofuturista. (MATANGRANO, 2016, s/p)

O movimento urbano da cidade do Rio de janeiro é descrito no diário particular de Isaías Caminha, um personagem que é jornalista na versão de Tavares. Isaías Caminha se prepara para investigar um assassino em série chamado Dr. Louison, na cidade de Porto Alegre dos Amantes e, em seu diário o espaço steampunk é descrito com zepelins, tecnologia aerostática, balão elíptico e robôs que fazem parte do cotidiano da sociedade. Assim, Caminha encontra belezas nos sabores e dessabores e no alvoroço da metrópole de tecnologia avançada.

As possibilidades retrofuturistas sugeridas no enredo promovem uma constatação das descobertas da ciência em um extenso contínuo, como se estivessem em uma engrenagem infinita de invenções. Observamos a minuciosa descrição dos detalhes tecnológicos desde o início da jornada de Isaías Caminha, a exemplo do trecho a seguir, quando há uma descrição sonora da máquina que leva Caminha a Porto alegre: "Quando partimos, lenta e calmamente, a excitação e as conversas deram lugar, como em toda a viagem, ao silêncio, quebrado vez ou outra pelo barulho das hélices ou pelo movimento das pás metálicas, responsáveis pelo empuxo da subida e pelo direcionamento do barco aéreo" (TAVARES, 2014, p.18).

Caminha confere a sua valise tecnojornalística que contém documentos da investigação referente a Antonine Frederico Louison, e utiliza um monóculo tecnostático para ler as descrições do assassino. O monóculo tecnostático e o barco aéreo são recursos recriados do steampunk. Identificamos que Tavares vale- 
se de elementos tecnológicos reais ou inventados, ao longo da viagem de seu personagem, para engendrar e construir o discurso ficcional steampunk.

O barco aéreo demarca uma narrativa ficcional de aparatos imaginários, porém possíveis pela ciência e tecnologia conforme se aventava para o tempo futuro, no século XIX. O monóculo tecnostático também provoca o mesmo estranhamento para o leitor. Esse contexto de descrições auxilia o leitor a mergulhar, gradativamente, pelo universo das engrenagens do steampunk.

No romance de Tavares, os transportes elétricos são recursos importantes de transporte, os quais conferem certa agilidade à narrativa, enquanto se acompanha os caminhos do jornalista, que informa: "tomei um bonde eléctrico até o miolo da capital riograndense" (TAVARES, 2014, p.23). Além da descrição do bonde elétrico, percebemos a presença do fogo elétrico e das carruagens robóticas que sugerem a energia da cidade em pleno desenvolvimento, reservando surpresas ao visitante de primeira viagem:

Diante dos olhos sonolentos, desviei do vaivém da rua lateral e mirei a indefinição de árvores e relvas, salpicadas pelos feixes de fogo eléctrico. Abaixo da vista, carruagens robóticas levavam e traziam os viandantes noturnos, enquanto cortesãs passeavam. (2014, p.26)

No fragmento da obra que segue, o autor descreve que o gás hélio, as carruagens mecânicas com motores acoplados e o "cinematógrapho", juntamente com um "phonógrapho", produzem "photogramas" e são característica da união da arte com a ciência, os quais evocam o contexto cultural do passado, pelo emprego 
arcaico do "ph" como " $f$ ". No trecho a seguir, tal emprego combina com imagens retrofuturistas:

Nos céus, grandes balões de gás hélio faziam viagens turísticas e comerciais. Falava-se até de um grande invento, uma aeronave gigantesca que poderia viajar rapidamente de Porto Alegre a São Paulo e levar passageiros até o Rio de Janeiro. Em terra, outras invenções surgiam: carruagens mecânicas, guiadas não por cavalos, mas com motores acoplados; bondes eléctricos, lentos e charmosos, que conectavam pontos distantes da cidade; e também as Casas de Variedades, que agora apresentavam aquele portento, maravilha das maravilhas, um tipo de cinematógrapho acoplado a um phonógrapho que produzia photogramas em movimento unidos à voz e à música. (TAVARES, 2014, p.246)

Os robôs também vivem nessa ficção de Enéias Tavares, contudo, eles não podem adentrar nos Palacetes do Prazeres de Porto Alegre dos Amantes. Cabe, porém, examinarmos o conceito acerca do robô na ficção científica. Em 1920, o escritor checo Karel Čapek sugeriu o nome robô para os seus personagens na sua peça teatral intitulada Robôs Universais de Rossum (R.U.R). Nessa peça existe um fábrica que cria pessoas artificiais ou escravos mecânicos elaborados com material sintético e que trabalham para os humanos. No entanto, eles se rebelam após descobrirem que seus poderes destroem a raça humana. A etimologia da palavra robô surgiu da palavra checa robota, que significa "servidão", "escravizados" ou "trabalho forçado". Segundo o Dicionário digital do insólito ficcional (2019), a figura do autômato foi mencionada desde a Antiguidade e a Idade Média, surgindo, por exemplo, como 
o Golem (do hebraico "um homem sem alma"). Outro exemplo que está articulado ao conceito é o autômato, que tem origem na llíada, de Homero, de acordo com o Dicionário digital do insólito ficcional (2019), descrito abaixo por Meireles:

Destaque-se que antes da criação dos termos "Androide", "Robô" e "Ciborgue", todo engenho com aparência de ser humano ou de outro animal capaz de reproduzir movimentos por meios mecânicos ou eletrônicos era chamado de "Autômato", cuja etimologia se liga ao grego automaton (auto, "próprio" + matos, "pensamento", "animado", "vontade"). Marcando presença na Literatura ocidental desde A llíada, de Homero na forma dos tripodes do deus Hefesto, o Autômato ressurgiu na Europa renascentista pelas mãos do italiano Leonardo da Vinci. (MEIRELES, 2019, s/p)

Na obra de Tavares, os robôs realizam trabalhos diversos, como os atendimentos em espaços de embarque e desembarque, conforme são vistos na viagem de Caminha, que foi atendido por um robô que não sinalizou a sua etnia correta, de acordo com o trecho a seguir:

Eu, obviamente, fui um dos últimos a embarcar, uma vez que minha cor mestiça sempre causava estranhamentos aos visores photosensíveis dos robóticos. Ao escutar a mensagem "etnia desconhecida", questionei-me sobre o absurdo daquela frase num país como o Brazil. Após encaminhar reclamação tipographada à companhia aérea, adentrei no movimentado compartimento. (TAVARES, 2014, p.18)

As questões que envolvem a cultura e as máquinas criadas pela ciência sugerem a possibilidade de reconhecimento facial avançado, 
porém neste caso a etnia de Caminha não é reconhecida pelo robô que já deveria estar preparado para esse tipo de eventualidade, em um país de população tão mestiça quanto a do Brasil:

Desci a escadaria e cheguei ao controle de passageiros, onde outro funcionário robótico checava os cartões. "Seja bem-vindo à capital do estado do Rio Grande do Sul", sibilou, por entre as engrenagens da face metálica. Seu movimento era automático, ora furando cartões, ora checando passageiros e tíquetes. A mim, desejou um "Faça uma boa viagem". (TAVARES, 2014, p.23)

Neste exemplo de steampunk brasileiro, as metrópoles como Rio de Janeiro e Porto Alegre ganham um novo desenho, trazendo páginas de aventura da liga do Pathenon para o leitor. Na narrativa, os robôs recebem cargos humanos, pois são revisores, cadetes, policiais, enfermeiros, secretários, diaristas e, por fim, realizam as gravações robóticas, por meio de uma forma segura de arquivar os registros diários dos personagens. O pano de fundo da narrativa é marcado por uma "segunda revolução mecânica", descrita a seguir:

Todos sabiam o que estava em jogo em tal mudança, não apenas em nosso país como também em todas as regiões do mundo. Estávamos, ao menos nos continentes civilizados, vivendo a Segunda Revolução Mecânica, com os servos robóticos mostrando-se cada vez mais eficientes e populares. (TAVARES, 2014, p.234)

A Revolução Industrial presente na narrativa desponta por um retrocesso social sem precedentes, pela substituição da mão de obra humana por máquinas e robôs. Roberts destaca que "a mobilização [das populações] era o espírito tutelar da época, a 
força motriz da Revolução Industrial; tecnologias de utilização da força a vapor, do transporte das massas, da manufatura e assim por diante, que havia muitos anos já eram conhecidas" (ROBERTS, 2018, p.222). Esse período foi descrito como a "Era da Mobilização" por Charles Taylor, que defendia "o progresso pelo qual as pessoas são persuadidas, empurradas, intimidadas ou coagidas a participar de novas formas de sociedade, de igreja e de associação, [...] não só adotar novas estruturas, mas também, até certo ponto, a alterar seu imaginário social" (ROBERTS Apud TAYLOR, 2018, p.222-223).

Nesse mesmo contexto, a personagem Beatriz de Almeida, filha de escravizados, afirma que "[n]as capitais, antes mesmo da extinção da escravidão, os homens ricos acharam por bem substituir serviçais escravos por robóticos" (TAVARES, 2014, p.234). A narrativa, portanto, denuncia um processo de mudança de mão de obra, com todas as suas implicações culturais, políticas e econômicas, elementos que a ficção científica tradicional pode escamotear, especialmente aquela de verniz mais utópica ou escapista. As consequências dessa Revolução Industrial são retratadas na obra de Tavares, conforme o fragmento da narrativa que segue:

Era toda uma revolução que se apresentava diante dos nossos olhos: pouco a pouco, domésticas, cocheiros, alcaides, agricultores e tantas outras profissões foram sendo substituídas por modelos mecânicos de grande potência, inteligência limitada e programação definida. (TAVARES, 2014, p.235)

A Revolução Industrial alastrou-se com uma velocidade impetuosa, sem promover condições de se compensar as problemáticas sociais surgidas no processo. Tavares recupera esse tempo de mudanças sociais e escreve em um ritmo 
narrativo gradual, explicitando que pouco a pouco as pessoas eram substituídas por modelos mecânicos, o que deflagra uma nova instância da dominação pela burguesia, da classe média e pobre. Essa problemática é apresentada no enredo com a voz da personagem Beatriz Souza, que é uma escritora e amante do assassino Louison. Ela é uma filha de escravizados que denuncia um Brasil repleto de problemas sociais históricos, descrevendo a vida de um escravizado entre o período do Império e da República. A personagem morava na fazenda Velhos Tempos, do coronel Aristeu, com sua esposa Matilde e sua filha Marieta. Nesse lugar, enquanto Matilde a ensina a ler e escrever, Beatriz conhece diversas histórias. É dessa personagem a afirmação que no dia 13 de maio de 1878 a Lei Áurea foi assinada pela Princesa Isabel.

Assim, com essa narrativa da ficção de Enéias Tavares, há um paralelo com a história brasileira, porém com a substituição do trabalho humano pelo trabalho técnico como a principal diferença: "era carne negra e indígena dando lugar à lata cinza" (TAVARES, 2014, p.235). É a personagem Beatriz quem nos conta essa experiência quem narra sobre como a mudança social acontece, quando a máquina robótica ganhou o espaço que era da mão de obra.

Esses movimentos do mundo robótico da narrativa evocam as transformações históricas em âmbito mundial, os quais foram impostas sobre o mundo social e do trabalho. Observamos que Caminha não recusa sua mudança de cidade, assim como os demais personagens em busca de novos horizontes e aventuras, o que nos auxilia a interpretar essa agitação da metrópole como um espaço de crescimento e de mudanças sociais e de imaginário, 
pois a sociedade secreta do Parthenom Místico é criada após as intimidações de uma elite da cidade que defende a reforma social e o progresso da produção.

\section{CONSIDERAÇÕES FINAIS}

Consideramos a obra A lição de anatomia do temível Dr. Louison (TAVARES, 2014) com o propósito de analisarmos os elementos do subgênero de ficção científica intitulado steampunk. Apreendemos, a partir deste estudo, que a ficção científica ganhou seu espaço com a Revolução Industrial e após a mobilização dos recursos da ciência, os quais colaboraram para o desenvolvimento das tecnologias transformadoras. É possível identificar que os eventos literários, as críticas e as obras voltadas à ficção científica ganharam no Brasil mais espaço e atenção nos últimos anos.

As personagens desse romance convidam-nos a repensar o nosso passado literário, histórico e político e, nesse ínterim, levamnos a tomada de consciência acerca das mudanças tecnológicas, científicas e sociais. Na perspectiva assinalada por Roberts (2018), esses movimentos da Revolução Industrial suscitaram para ficção científica possibilidades de dramatizar os fenômenos culturais em grande escala, com o propósito de auxiliar os seus criadores na criação dos mundos ficcionais a partir de grandes aparatos tecnológicos e de sociedades em transformação desumanizadora em grande escala.

Além disso, a literatura steampunk ajuda a ressignificar a literatura brasileira tradicional, favorecendo uma releitura de obras brasileiras como Doutor Benignus (1875), O ateneu (1888), O cortiço (1890) e Contos Amazônicos (1893). Vale destacar a importância 
desse resgate da literatura nacional imbricado nessa narrativa de ficção científica a fim de promover a formação de jovens leitores, motivando-os à leitura.

Naatualconjuntura, verifica-sea importância do reconhecimento de nossa tradição literária e de seus projetos recriados, cenário que localizamos a obra de Enéias Tavares e a série Brasiliana Steampunk. Sua natureza transmídia - constituída não apenas de romance, como também de quadrinhos, jogos, audiovisual e suplemento escolar - acabam por ampliar tanto o universo ficcional criado por Tavares como também promove a expansão de seu público (SILVA; AMARAL, 2019), muitos deles presentes no website do projeto: www.brasilianasteampunk.com.br.

Desse modo, ao adotar novos "braços" transmídia a partir da narrativa literária "raiz", Brasiliana Steampunk se mostra não apenas afinado com uma releitura crítica do passado como também em profundo diálogo com fenômenos tecnológicos e narrativos muito próprios da contemporaneidade. Essa leitura retrô e futurista do passado pode ser uma das muitas chaves de leitura para $A$ lição de anatomia do temível dr. Louison, um romance calcado no passado, no presente e, talvez, no futuro.

\section{REFERÊNCIAS}

CALEGARI, Lizandro Carlos; OLIVEIRA, Anderson Amaral (2018). “Um personagem, dois mundos: Isaías caminha em 1909 e em 2014". Revista Abusões, 7(7).

CAUSO, Roberto de Sousa (2015). "Esboço de uma história da crítica de ficção científica no Brasil". In: SUPPIA, Alfredo (Org.). Cartografias para a ficção científica mundial: cinema e literatura. São Paulo: Alameda.

CHAVES, Jaime (2018). "Cinema retrofuturista e steampunk: possíveis origens de um subgênero literário". Revista Abusões, 6(6), 239. 
COSTA, Joana Garcia (2017). Steampunk: Utopismo e Neovitorianismo nos séculos $X X$ e XXI. In https://run.unl.pt/bitstream/10362/11930/1/Steampunk\%20 Utopismo\%20e\%2Neovitorianismo\%20nos\%20s\%C3\%A9culos\%20XX\%20e\%20 XXI.pdf Acesso em 20.Jul.2017.

KRISTEVA, Julia (1974). Introdução à semanálise. São Paulo: Perspectiva.

MARTINS, Jucélia de Oliveira; SANTOS, Naiara Sales Araújo (2019). “A robótica e a ficção científica: primeiras interações". In Darandina revista eletrônica. Programa de pós-graduação em Letras, UFJF, 12(1).

MATANGRANO, Bruno Alsemi (2016). "O olhar contemporâneo na releitura do moderno: A lição de anatomia do temível Dr. Louison". Estudos de Literatura Brasileira Contemporânea, Brasília, 48, Mai./Ago.

; TAVARES, Enéias (2018). Fantástico brasileiro: O insólito literário do Romantismo ao Fantasismo. Curitiba, PR: Arte \& Letras.

MEIRELES, Alexandre (2019). Dicionário Digital do Insólito Ficcional. SEPEL. In http://www.insolitoficcional.uerj.br/site/a/automato-androide-ciborgue-robo/ Acesso em 10.Out.2019.

OLIVEIRA, Nelson de (2018). Fractais Tropicais: o melhor da ficção científica brasileira. SESI: São Paulo.

PEGORARO, Éverly. (2012a). “Os steampunks e a cultura da mídia: apropriações de uma proposta retrofuturista no cenário brasileiro". Revista Mediaciones Sociales, Madri, 11(2), 72-94. In http://goo.gl/BKjuva Acesso em 20.Jul.2019.

(2012b). "Steampunk: as transgressões temporais negociadas de uma cultura retrofuturista". Cadernos de Comunicação, UFSM, 16(2), 389-400. In https://periodicos.ufsm.br/index.php/ccomunicacao/article/view/8236/4956 Acesso em 20.Jul.2017.

(2015). No compasso do Tempo Steampunk: A canção do silêncio.

ROBERTS, Adams (2018). A verdadeira história da ficção científica: do preconceito à conquista das massas. São Paulo: Seonman.

SILVA, Suellen Cordovil; AMARAL, Anderson de Oliveira (2019). “Um estudo de caso de narrativa transmídia: 'A lição de Anatomia do Dr. Louison' de Enéias Tavares". In: ROCHA, Cleomar; GROISMAN, Martin (Orgs). Anales del VI Simpósio Internacional de Innovación en Medios Interactivos. Mutaciones. Buenos Aires: 
Media Lab/Universidad de Buenos Aires. In https://siimi.medialab.ufg.br/ p/29801-anais-2019 Acesso em 31.Jan.2020.

TAVARES, Enéias (2014). A Lição de Anatomia do Temível Dr. Louison. Rio de Janeiro: Casa da Palavra.

TORRES, Marcos. (2017) Afinal, o que é Retrofuturismo? In http://designculture. com.br/afinal-o-que-e-retrofuturismo/ Acesso em 17.Jul.2017.

VANDERMEER, Jeff; CHAMBERS, S. J. (2011). The Steampunk bible: an illustrated guide to the world of imaginary airships, corsets and goggles, mad scientists, and strange literature. China: Abrams Image. 